\title{
PENGARUH TRANSFORMATIONAL LEADERSHIP TERHADAP WORK ENGAGEMENT YANG DIMEDIASI OLEH MEANING IN WORK DAN PERSONAL RESOURCE
}

\author{
Wahyu Prabawati Putri Handayani1 \\ Didik Joko Pitoyo
}

\author{
Fakultas Ekonomi dan Bisnis, Universitas Katolik Widya Mandala Madiun \\ wahyu.prabawatii@gmail.com, didikjokopitoyo@gmail.com
}

\begin{abstract}
This research posses the objectives to analyze the influence of transformational leadership on work engagement through meaning in work and personal resources as mediation variables. This study involved 120 respondents of outsorced employee from 13 Divisions at PT Industri Kereta Api (Persero) and this study used path analysis to test the hypothesis. This study proves that transformational leadership have significant positive influence on work engagement, meaning in work, and personal resources. Personal resources and meaning in work can also perform as mediating variables for relationship between transformational leadership on work engagement. Mediating effect that can be found in this research is partial mediating effect type. It was proved by the direct relationship between transformational leadership and work engagement keep significantly positive when it was mediated by meaning in work and personal resources eventhough the significant level is declining.
\end{abstract}

Keyword : transformational leadership, work engagement.

\begin{abstract}
ABSTRAK
Penelitian ini untuk menganalisis pengaruh dari transformational leadership terhadap work engagement melalui meaning in work dan personal resource sebagai variabel mediasi. Penelitian ini melibatkan 120 responden yaitu karyawan Perjanjian Kerja Waktu Tertentu (PKWT) dari 13 Divisi di PT Industri Kereta Api (Persero). Penelitian ini menggunakan alat analisis dengan metode analisis path. Penelitian ini mendapatkan temuan bahwa transformational leadership memiliki pengaruh signifikan positif terhadap work engagement, meaning in work, dan personal resource. Personal resource dan meaning in work juga dapat berperan sebagai mediator antara transformational leadership terhadap work engagement. Peran mediator yang ditemukan oleh peneliti adalah mediasi secara parsial. Terbukti dari hubungan langsung antara transformational leadership dan work engagement tetap signifikan positif pada hubungan tidak langsung ketika melalui variabel mediasi yaitu meaning in work dan personal resource.
\end{abstract}

Keyword : transformational leadership, work engagement.

\section{PENDAHULUAN}

Perkembangan transportasi perkeretaapian di Indonesia dan negera-negara pada kurun waktu lima tahun terakhir memberikan dampak positif bagi bisnis PT Industri Kereta Api (Persero), sehingga saat ini PT INKA (Persero) mengalami pertumbuhan cukup pesat sebagai penyedia sarana perkeretaapian terbesar di Asia Tenggara. Hal ini menuntut PT INKA (Persero) untuk melakukan rekrutmen karyawan Perjanjian Kerja Waktu Tertentu (PKWT) dalam skala yang cukup besar. Dalam hal ini PT INKA 
(Persero) banyak membutuhkan karyawan yang dapat diarahkan dan memiliki pemahaman terkait dengan pekerjaan. Oleh karena itu, work engagement karyawan sangat diperlukan untuk mengatasi apapun tuntutan kerja yang diterima (Schaufeli \& Bakker, 2003).

Work engagement adalah sikap positif dalam memenuhi kondisi sebuah pekerjaan dan ditandai oleh kekuatan, dedikasi, dan daya serap terhadap informasi (Schaufeli, Salanova, Gonzales, dan Bakker, 2002). Aspek yang mempengaruh work engagement di PT INKA (Persero) dilihat dari Key Job Accountability (KJA), disiplin, serta kompetensi. Hal inilah yang menja

di acuan untuk menilai kinerja individu karyawan. Selain itu, PT INKA (Persero) juga membutuhkan pemimpin yang memiliki gaya transformational leadership yang mampu memotivasi serta menginspirasi pengikut dengan tujuan mendorong pengikut ke arah yang lebih baik (Bass, 1991). Berkaitan dengan hal tersebut, Podolny (2005) menemukan bahwa pemimpin mempunyai peran penting untuk mempengaruhi pemahaman kerja para pengikutnya. Meaning in work menurut Arnold, Turner, Barling, Kelloway, dan McKee (2007) terjadi ketika pekerjaan memiliki tujuan, nilai yang terhubung ke pengikut, dan kemampuan untuk membangun makna dalam pekerjaan (Chalofsky, 2003).

Meaning in work mampu memprediksi work engagement karena merupakan faktor motivasi intrinsik (May, Gilson, dan Harter, 2004). Transformational leadership pada hakikatnya akan memotivasi pengikut, membangkitkan semangat, dan meningkatkan personal resource (optimisme dan self-efficacy) dalam mencapai tujuan perusahaan (Xanthopoulou, Bakker, Demerouti, dan Schaufeli, 2009). Personal resources menunjukkan bahwa beberapa evaluasi diri yang positif memprediksi goal-setting, motivasi, kinerja, kepuasan kerja, kepuasan hidup, dan hal menarik lainnya.

\section{TINJAUAN PUSTAKA Work Engagement}

Work engagement adalah suatu sikap positif yang terkait dengan pekerjaan yang digunakan untuk memenuhi kondisi dalam pekerjaan yang ditandai dengan vigor, dedication, serta absorption (Schaufeli et al., 2002). Aspek vigor merupakan suatu aspek yang ditandai dengan tingginya tingkat kekuatan dalam bekerja, keinginan untuk berusaha dengan sungguh-sungguh di dalam pekerjaan, dan sikap gigih dalam 
menghadapi kesulitan. Aspek dedication merupakan suatu aspek yang ditandai oleh perasaan yang penuh makna, antusias, inspirasi, kebanggaan dan menantang dalam pekerjaan. Aspek absorption merupakan suatu aspek yang ditandai dengan individu memiliki konsentrasi yang tinggi terhadap pekerjaan, menikmati pekerjaan, merasa waktu terasa cepat saat bekerja dan merasa sulit untuk melepaskan diri dari pekerjaan (Schaufeli \& Bakker, 2003).

\section{Transformational Leadership}

Definisi dari transformational leadership merupakan tipe pemimpin yang mampu menggerakkan pengikut melalui karisma, inspirasi, stimulasi, serta pendekatan yang dimiliki pemimpin (Bass, 1999). Menurut Bass, Avolio, Jung, dan Berson (2003) terdapat 4 dimensi transformational leadership: (1) idealized influence; (2) pengembangan intelektual intellectual stimulation; (3) inspirational motivation; (4) individualized consideration.

\section{Meaning in Work}

Terjadi ketika pengikut mempersepsikan pekerjaannya memiliki tujuan dan nilai yang saling terhubung dengannya (Arnold et al., 2007). Dimensi meaning in work menurut Morin (2008) terdiri dari sensus, sumo, dan fenomologi. Sensus berkaitan dengan values, yaitu nilai pekerjaan dalam pandangan pengikut atau pentingnya kerja dalam pandangan pengikut. Sumo berkaitan dengan motivations, yaitu apa yang pengikut cari dalam pekerjaan. Fenomologi berkaitan dengan beliefs about work, yaitu efek koherensi antara pengikut dan pekerjaannya, nilai-nilai dan tindakan untuk melakukan pekerjaan setiap hari di lingkungan kerja.

\section{Personal Resource}

Personal resource merupakan evaluasi pribadi yang positif berkaitan dengan kemampuan untuk mengendalikan diri dalam mencapai kesuksesan yang bisa memberikan dampak pada lingkungan (Hobfoll, Johnson, Ennis \& Jackson, 2003). Dimensi personal resources menurut Hobfoll et al. (2003) adalah self efficacy dan optimism. Self-efficacy merupakan kemampuan diri yang dipersepsikan oleh seorang individu untuk melaksanakan serta menyelesaikan tugas dalam berbagai konteks. Sedangkan optimism merupakan keyakinan akan potensi yang dimiliki oleh seseorang untuk berhasil atau sukses.

Gambar 1 merupakan pengembangan model penelitian. 


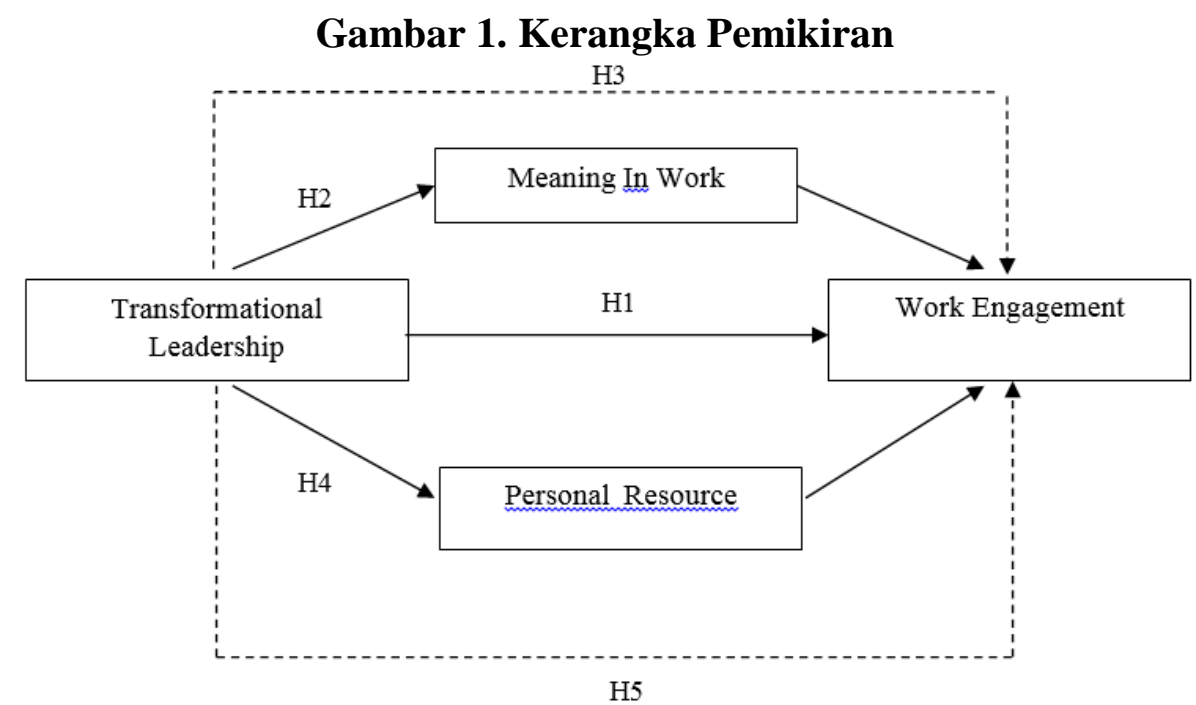

Sumber : Pengembangan Model penelitian Ghadi et al., (2013) \& Bakker (2011)

\section{Relasi transformational leadership terhadap work engagement}

Bass (1991) menjelaskan bahwa transformational leadership terjadi ketika pemimpin dapat memenuhi kebutuhan pengikut, membangkitkan kesadaran pengikut, dan menggerakkan pengikut untuk lebih peka terhadap kepentingan kelompok diatas kepentingan pribadi. Ghadi et al. (2013) dalam penelitiannya terhadap hubungan transformational leadership pada work engagement mendapatkan hasil bahwa transformational leadership memiliki pengaruh signifikan positif terhadap work engagement. Dalam penelitian yang lain, Susetyo (2015) juga menemukan hasil bahwa transformational leadership mempunyai pengaruh signifikan positif terhadap work engagement.

H1: Transformational leaderhip berpengaruh signifikan pada work engagement.

\section{Relasi antara transformational leadership terhadap meaning in work}

Ghadi et al. (2013) dalam penelitiannya mengenai keterkaitan transformational leadership terhadap meaning in work memperoleh hasil bahwa transformational leadership mempunyai pengaruh signifikan terhadap meaning in work. Ghadi et al. (2013) lebih dalam menyatakan bahwa transformasional leadership dapat menciptakan meaning in work pengikut. Susetyo (2015) dalam penelitiannya dengan menggunakan variabel yang sama, menunjukkan hasil bahwa transformasional leadership berpengaruh positif pada meaning in work. Lebih lanjut Susetyo (2015) menyatakan bahwa dengan adanya pemimpin yang mempunyai gaya transformasional leadership maka pemahaman pengikut mengenai makna kerja akan meningkat. 
H2: Transformational leaderhip berpengaruh signifikan pada meaning in work.

\section{Relasi antara transformational leadership terhadap work engagement melalui mediasi meaning in work}

Ghadi et al. (2013) dalam penelitiannya menemukan bahwa hubungan transformational leadership terhadap work engagement didukung oleh mediasi meaning in work secara signifikan. Lebih lanjut Ghadi et al. (2013) menjelaskan temuan penelitian sebelumnya Bakker, Albrecht, dan Leiter (2011) yang mengklaim bahwa hubungan transformational leadership terhadap work engagement dapat dimediasi oleh meaning in work. Susetyo (2015) dalam penelitiannya memperkuat penelitian Ghadi et al. (2013) dan Bakker et al. (2011) yang menyatakan bahwa meaning in work dapat memediasi hubungan transformational leadership pada variabel work engagement secara parsial.

H3: Transformational leaderhip berpengaruh signifikan pada work engagement melalui mediasi meaning in work.

\section{Relasi antara transformational leadership terhadap personal resource}

Personal resource merupakan sikap positif dari evaluasi pribadi berkaitan dengan kemampuan mengendalikan diri dalam mencapai kesuksesan (Hobfoll, Johnson, Ennis \& Jackson, 2003). Kark, Shamir \& Chen (2003) menjelaskan dimensi personal resource yaitu self efficacy dapat ditingkatkan melalui transformational leadership. Bakker et al. (2011) dalam penelitiannya menemukan bahwa variabel transformational leadership dapat mempengaruhi kepercayaan diri pengikut (yaitu personal resource) dan pengalaman kerja (yaitu work engagement).

H4: Transformational leaderhip berpengaruh signifikan pada personal resource.

\section{Relasi antara transformational leadership terhadap work engagement melalui mediasi personal resource}

Personal resource merupakan prediksi yang menunjuk pada tujuan, motivasi, performa, pekerjaan dan kepuasan hidup (Hobfoll, Johnson, Ennis \& Jackson, 2003). Bakker et al. (2011) dalam penelitiannya menunjukkan bahwa personal resource memiliki peranan sebagai mediator ditunjukan dengan optimism yang berperan sebagai full mediation dari hubungan transformational leadership terhadap work engagement. Lebih dalam Bakker (2011) menjelaskan bahwa pengikut menjadi lebih engaged dengan 
pekerjaan ketika pemimpin mampu meningkatkan optimism melalui transformational leadership.

H5: Transformational leaderhip berpengaruh signifikan pada work engagement melalui mediasi personal resource.

\section{METODE PENELITIAN}

Pada penelitian ini pendekatan kuantitatif digunakan sebagai desain penelitian dengan menekankan analisis data numerikal yang diolah menggunakan metode statistika. Tujuannya adalah untuk menguji hipotesis yang telah dikembangkan dan menguji korelasi hubungan variabel yang membentuk suatu model.

\section{Populasi, Sampel, dan Teknik Sampling}

PT Industri Kereta Api (Persero) merupakan perusahaan manufaktur yang bergerak dalam bidang sarana transportasi khususnya kereta api dengan status Badan Usaha Milik Negara yang berdiri tanggal 18 Mei 1981. Sejak pendiriannya PT Industri Kereta Api (Persero) terletak di Jl. Yos Sudarso No. 71 Kota Madiun.

Populasi dalam penelitian ini adalah seluruh karyawan PKWT (Perjanjian Kerja Waktu Tertentu). Sampel penelitian sebanyak 120 orang yang diambil dari 13 Divisi. Penelitian ini menggunakan proportional random sampling sebagai teknik pengambilan sampel yang merupakan pengambilan sampel secara proporsi dan dilakukan dengan mengambil subyek dari setiap Divisi yang sudah ditentukan dengan seimbang (Arikunto, 2006).

\section{HASIL \& PEMBAHASAN}

Uji reliabilitas instrumen dalam penelitian ini menggunakan Cronbach Alpha dengan nilai batas 0,7 untuk construct reliability. Hasil menunjukkan bahwa semua instrumen pernyataan reliabel karena mempunyai nilai $>0,7$.

\section{Tabel 1. Hasil Uji Reliabilitas}

\begin{tabular}{clc} 
No & \multicolumn{1}{c}{ Variabel } & Construct Reliability \\
\hline 1 & Transformational leadership & 0,954 \\
2 & Meaning in work & 0,881 \\
3 & work engagement & 0,965 \\
4 & Personal resources & 0,934 \\
\hline
\end{tabular}


Dalam penelitian ini nilai $\chi^{2}$ menghasilkan tingkat signifikansi lebih besar dari 0,05 dengan nilai $\chi^{2}$ sebesar 1,335 menunjukkan bahwa model yang diajukan peneliti sudah memenuhi. Nilai CMIN/DF, GFI, AGFI, TLI, CFI, dan RMSEA dalam model penelitian ini menunjukkan tingkat kesesuaian yang baik.

Tabel 2. Hasil Goodness-of-Fit Model

\begin{tabular}{llcc}
\multicolumn{1}{c}{ Goodness-of-fit Indices } & Cut-off Value & Hasil & Evaluasi Model \\
\hline Chi-Square $\left(\chi^{2}\right)$ & Diharapkan kecil & 1,335 & Fit \\
Degrees of freedom & Positif & 1 & Fit \\
Probability level $(p)$ & $\geq 0,05$ & 0,248 & Fit \\
CMIN/DF & $\leq 2,0$ & 1,335 & Fit \\
GFI & $\geq 0,90$ & 0,994 & Fit \\
AGFI & $\geq 0,90$ & 0,945 & Fit \\
TLI & $\geq 0,95$ & 0,945 & Fit \\
CFI & $\geq 0,95$ & 0,991 & Fit \\
RMSEA & $\leq 0,08$ & 0,053 & Fit \\
\hline
\end{tabular}

Sumber: Data primer diolah, 2018

\section{Pengaruh Transformational Leadership Pada Work Engagement}

Tabel 3. Hasil Analisis Transformational Leadership terhadap Work Engagement

\begin{tabular}{cc} 
Transformational Leadership $\rightarrow$ Work Engagement \\
\hline Estimate & .240 \\
S.E. & .103 \\
C.R. & 2.316 \\
P & .021 \\
\hline
\end{tabular}

Sumber: Data primer diolah, 2018

Nilai CR transformational leadership pada work engagement yang ditunjukkan oleh tabel 3 adalah sebesar 2.316 dengan tingkat signifikansi 0,021. Nilai $p<0,05(0,021<$ 0,05), sehingga disimpulkan bahwa transformational leadership berpengaruh signifikan pada work engagement sehingga hipotesis 1 didukung dalam penelitian ini.

Fenomena ini dapat terjadi karena para pemimpin memiliki tingkat kehati-hatian yang tinggi dalam mendengarkan dan memenuhi kebutuhan yang diharapkan oleh para pengikutnya, para pemimpin juga menerapkan coaching dan mentoring yang baik pada pengikutnya dengan memberikan tantangan pekerjaan sehingga pengikut dapat mengaktualisasikan diri lebih baik. Transformational leadership yang ada ditunjukan dengan pemimpin-pemimpin yang memberikan visi bersama dan misi yang kuat sehingga pengikut dapat mengidentifikasi tujuan pemimpin dengan baik. Peran transformational leadership yang tinggi menciptakan komitmen yang kuat dari para pengikut sehingga para pengikut merasa terikat dalam pekerjaan, dibuktikan dengan daya serap pengikut yang 
tinggi pada pengalaman dan pengetahuan yang diberikan oleh pimpinan, dedikasi yang baik dalam pekerjaan, dan ketahanan serta kekuatan didalam pekerjaan.

Penelitian ini menemukan hasil yang sejalan dengan_Ghadi et al. (2013) bahwa work engagement dipengaruhi oleh transformational leadership. Penelitian ini juga serupa dengan penelitian Susetyo (2015) yang menemukan bahwa work engagement dipengaruhi secara signifikan terhadap transformational leadership.

Tabel 4. Hasil Analisis Data Transformational Leadership terhadap Meaning In Work

\begin{tabular}{cc} 
Transformational Leadership $\rightarrow$ Meaning In Work \\
\hline Estimate & .247 \\
S.E. & .098 \\
C.R. & 2.506 \\
P & .012 \\
\hline
\end{tabular}

Sumber: Data primer diolah, 2018

Nilai CR transformational leadership pada meaning in work yang ditunjukkan oleh tabel 4 adalah sebesar 2.506 dengan tingkat signifikansi 0,012. Nilai $p<0,05(0,012<$ 0,05), maka dapat disimpulkan bahwa transformational leadership berpengaruh signifikan pada meaning in work, sehingga hipotesis 2 didukung dalam penelitian ini. Fenomena ini dapat terjadi karena pemimpin terbuka dalam proses mentoring terhadap pengikutnya sehingga terjalin komunikasi yang baik, hal ini menjadikan kepercayaan dalam bekerja dari para pengikut menjadi semakin tinggi.

Pemberian kesempatan yang diberikan oleh pemimpin kepada pengikut berupa tantangan dalam pekerjaan, membuat para pengikut semakin termotivasi dan merasa diri semakin bernilai di dalam pekerjaannya. Penelitian ini menemukan hasil yang serupa dengan penelitian Ghadi et al. (2013) bahwa transformational leadership berpengaruh signifikan terhadap meaning in work. Penelitian Susetyo (2015) juga sejalan dengan penelitian ini yang mendapatkan hasil bahwa transformasional leadership berpengaruh positif secara signifikan terhadap meaning in work.

Gambar 2. Meaning In Work Sebagai Variabel Pemediasi Hubungan Antara Transformational Leadership Dan Work Engagement 


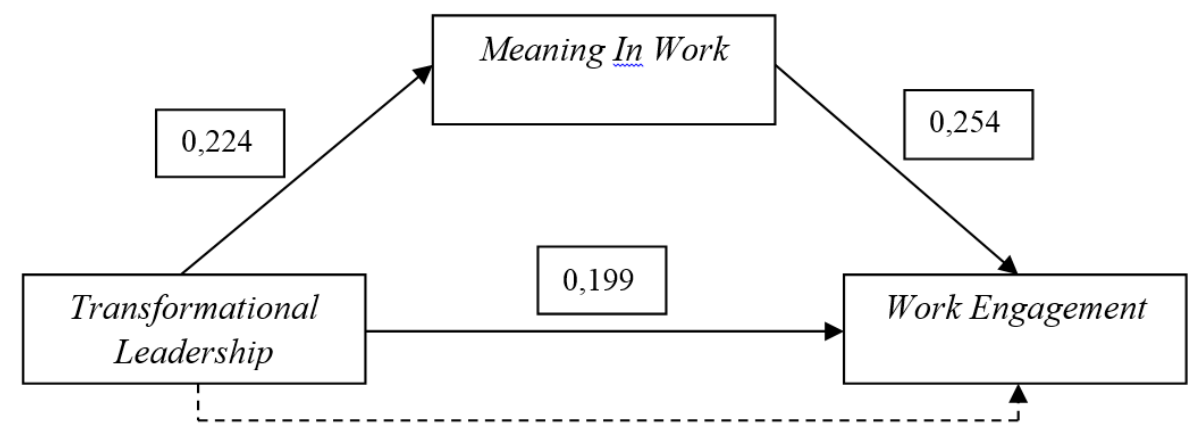

Tabel 5. Hasil Analisis Data Mediasi Meaning In Work pada Transformational Leadership terhadap Work Engagement

\begin{tabular}{ccc} 
Keterangan & $\begin{array}{c}\text { Transformational } \\
\text { leadership } \rightarrow \text { Work } \\
\text { engagement }\end{array}$ & $\begin{array}{c}\text { Transformational } \\
\text { leadership } \rightarrow \text { Meaning in } \\
\text { work } \rightarrow \text { Work engagement }\end{array}$ \\
\hline Pengaruh Langsung & 0.199 & - \\
Pengaruh Tidak langsung & - & $0.224 \times 0.254=0.057$ \\
Pengaruh Total & - & $0.199+0.057=0.256$
\end{tabular}

Sumber: Data primer diolah, 2018

Berdasarkan perhitungan pada analisis jalur, pengaruh langsung transformational leadership pada work engagement lebih besar dibandingkan pengaruh tidak langsung, yaitu jika melalui mediasi meaning in work. Akan tetapi, karena hasil dari pengaruh tidak langsung masih signifikan maka disimpulkan bahwa transformational leadership mempunyai pengaruh signifikan positif pada work engagement melalui variabel intervening meaning in work dengan partial mediation, sehingga dapat disimpulkan bahwa hipotesis 3 didukung. Fenomena ini terjadi disebabkan kuatnya transformational leadership sehingga mampu secara langsung mempengaruhi keterikatan kerja dari para pengikutnya. Pada pengaruh tidak langsung, dalam membentuk work engagement pengikut, transformational leadership dapat melibatkan meaning in work dari setiap pengikutnya karena pemahaman akan pekerjaan menjadi sesuatu yang sangat bermakna, seperti betapa pentingnya pekerjaan untuk dilakukan, pentingnya berkontribusi bagi perusahaan, pentingnya suatu tanggung jawab dan bentuk kebanggaan seperti apa yang ingin dicapai.

Transformational leadership dapat membantu pengikut dalam menemukan makna dengan meningkatkan kualitas intrinsik dari pekerjaan itu sendiri atau lingkungan kerja, dengan cara melatih dan memberikan nasihat pada pengikut, meningkatkan aktualisasi diri pengikut, selalu menyampaikan visi bersama dan meningkatkan misi yang bermanfaat. Ketika transformational leadership dapat menciptakan meaning in work bagi 
pengikutnya, ini akan membantu transformational leadership dalam membentuk work engagement.

Hasil penelitian ini sejalan dengan penelitian Ghadi et al. (2013) yang mendapatkan hasil bahwa mediasi meaning in work mendapat dukungan yang signifikan pada hubungan antara transformational leadership terhadap work engagement. Hasil penelitian Susetyo (2015) juga mendukung hasil penelitian ini yang menemukan bahwa meaning in work dapat memediasi secara parsial antara transformational leadership terhadap work engagement.

Tabel 6. Hasil Analisis Data Transformational Leaderhip Terhadap Personal Resource

Transformational Leadership $\rightarrow$ Personal Resource

\begin{tabular}{cc}
\hline Estimate & .248 \\
S.E. & .096 \\
C.R. & 2.583 \\
P & .010 \\
\hline
\end{tabular}

Sumber: Data primer diolah, 2018

Hasil analisis jalur pada Tabel 6 menunjukkan nilai c.r transformational leadership pada personal resources sebesar 2,583 dengan tingkat signifikansi 0,010. Nilai $p<0,05$ $(0,010<0,05)$, maka dapat disimpulkan bahwa terdapat pengaruh signifikan transformational leadership pada personal resources sehingga hipotesis 4 didukung. Fenomena ini dapat terjadi karena pemimpin memberikan motivasi yang baik pada pengikutnya dengan memberikan contoh melalui dirinya, para pimpinan juga meningkatkan semangat tim melalui pelatihan, mendorong pengikutnya untuk mencapai lebih banyak dalam kepentingan kelompok daripada mencapai kepentingan pribadi mereka sendiri sehingga self efficacy dan optimisme pengikut menjadi tinggi.

Transformational leadership berusaha mendorong pengikutnya untuk inovatif dan kreatif dalam menangani masalah sehingga persepsi diri pengikut akan kemampuan yang dimiliki menjadi tinggi. Optimisme pengikut dipengaruhi oleh transformational leaderhip karena kemampuan pimpinan dalam mentransform pengikut menjadi lebih baik dan semakin meningkat, sehingga menjadikan pengikut yakin akan kemampuan yang dimiliki dalam menghadapi pekerjaan.

Hasil penelitian ini serupa dengan penelitian_Bakker et al. (2011) yang menemukan hasil bahwa transformational leadership mempunyai pengaruh signifikan pada personal resource. 


\section{Gambar 3. Personal Resource Sebagai Variabel Pemediasi Hubungan Antara Transformational Leadership Dan Work Engagement}

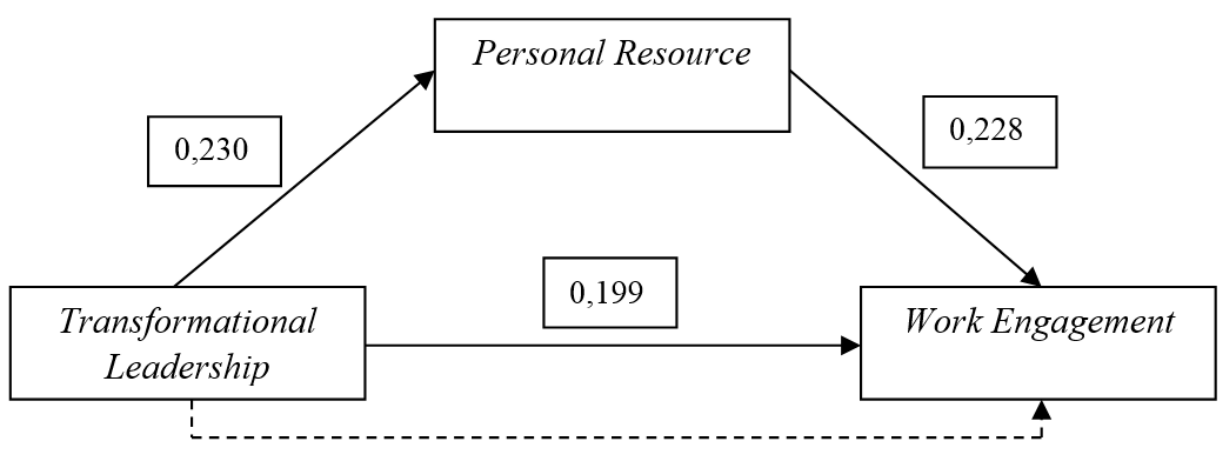

Tabel 7. Hasil Analisis Data Mediasi Meaning In Work pada Transformational Leadership terhadap Work Engagement

\begin{tabular}{ccc} 
Keterangan & $\begin{array}{c}\text { Transformational } \\
\text { leadership } \rightarrow \text { Work } \\
\text { engagement }\end{array}$ & $\begin{array}{c}\text { Transformational } \\
\text { leadership } \rightarrow \text { Personal } \\
\text { resources } \rightarrow \text { Work } \\
\text { engagement }\end{array}$ \\
\hline $\begin{array}{c}\text { Pengaruh Langsung } \\
\text { Pengaruh Tidak langsung }\end{array}$ & 0.199 & - \\
Pengaruh Total & - & $0.230 \times 0.228=0.052$ \\
\hline
\end{tabular}

Sumber: Data primer diolah, 2018

Berdasarkan perhitungan analisis jalur, transformational leadership mempunyai pengaruh langsung lebih besar pada work engagement dibandingkan pengaruh tidak langsung, yaitu jika melalui mediasi personal resource. Akan tetapi, karena hasil dari pengaruh tidak langsung masih signifikan maka disimpulkan bahwa transformational leadership mempunyai pengaruh signifikan positif pada work engagement melalui variabel intervening personal resource dengan partial mediation, sehingga dapat disimpulkan bahwa hipotesis 5 didukung. Fenomena ini dapat terjadi ketika transformational leadership dapat meningkatkan rasa optimisme pengikut. Optimisme yang kuat pada diri pengikut menghasilkan kekuatan dalam pekerjaan yang akan menghasilkan energi positif sehingga ketika menghadapi permasalahan dalam pekerjaan, pengikut tidak mudah putus asa atau mengalami stress dalam menyelesaikan masalah yang terjadi dalam pekerjaan. Hal ini membuat pengikut dapat lebih mendedikasikan dirinya dalam pekerjaan.

Transformational leadership juga meningkatkan keyakinan diri pengikut dengan cara melibatkan pengikut dalam pemecahan masalah secara inovatif dan kreatif. Selain itu, terbukanya pimpinan dalam berbagi pengetahuan dan pengalaman juga turut 
meningkatkan daya serap pengikut untuk kemajuan diri dan perusahaan.

Hasil penelitian ini serupa dengan penelitian Bakker et al. (2011) yang mendapatkan hasil bahwa mediasi personal resource mendapat dukungan signifikan pada hubungan antara transformational leadership terhadap work engagement.

\section{SIMPULAN \& SARAN \\ Simpulan}

Simpulan yang didapat dari penelitian ini berdasarkan analisis hasil dan pembahasan adalah sebagai berikut:

1. Transformational leadership memiliki pengaruh signifikan positif terhadap work engagement, meaning in work, dan personal resource.

2. Personal resource dan meaning in work juga dapat berperan sebagai mediator antara transformational leadership terhadap work engagement, peran mediator yang ditemukan adalah mediasi secara parsial dimana ketika hubungan langsung antara transformational leadership dan work engagement signifikan positif menjadi tetap signifikan positif pada hubungan tidak langsung ketika melalui variabel mediasi yaitu meaning in work dan personal resource.

\section{Saran}

1. Penjabaran work engagement yang lebih spesifik dapat dilakuan dengan pengukuran variabel work engagement.

2. Untuk meningkatkan tingkat kepercayaan dalam hasil penelitian, peneliti berikutnya dapat meningkatkan prosentase jumlah responden.

\section{DAFTAR PUSTAKA}

Arikunto, Suharsimi. 2006. Prosedur Penelitian : Suatu Pendekatan Praktik, Edisi Revisi VI, Jakarta : PT Rineka Cipta.

Arnold, K.A., Turner, N., Barling, J., Kelloway, E.K. and McKee, M.C. 2007. Transformational leadership and psychological well-being: the mediating role of meaningful work. Journal of Occupational Health Psychology. Vol. 12, No. 3, pp. 193-203.

Bakker, A.B., Albrecht, S.L. and Leiter, M.P. 2011. Key questions regarding work engagement. European Journal of Work and Organizational Psychology. Vol. 20, No. 1 , pp. $4-28$

Bass, B. M. 1991. From transactional to transformational leadership: Learning to share the vision. Organizational dynamics, Vol. 18, No. 3, pp. 19-31 
Bass, B. M. 1999. Two decades of research and development in transformational leadership. European journal of work and organizational psychology, 8(1), 9-32.

Bass, B.M., B.J. Avolio, D.I. Jung \& Y. Berson. 2003. Predicting unit performance by assessing transformational and transactional leadership.। Journal of Applied Psychology. Vol. 88, No. 2, pp. 207-218.

Chalofsky, N. 2003. Meaningful Work. Training and Development Journal, Vol. 57, No. 12 , pp. $52-58$.

Ghadi, M.Y., Fernando, M., Caputi, P. 2013. Transformational leadership and work engagement The mediating effect of meaning in work. Leadership \& Organization Development Journal, Vol. 34, No. 6, pp. $532-550$.

Hobfoll, S. E., Johnson, R. J., Ennis, N. E., \& Jackson, A. P. 2003. Resource loss, resource gain, and emotional outcomes among inner-city women. Journal of Personality and Social Psychology, No. 84, pp. 632-643.

Kark, R., Shamir, B., \& Chen, G. 2003. The Two Faces Of Transformational Leadership: Empowerment and Dependency. Journal Of Applied Psychology. Vol. 88, No. 2, pp. 246-255

May, D. R., Gilson, R. L., \& Harter, L. M. 2004. The psychological conditions of meaningfulness, safety and availability and the engagement of the human spirit at work. Journal of Occupational and Organizational Psychology, No. 77, pp. 1137.

Morin, E. M. 2008. The meaning of work, mental health and organizational commitment. Sao Paulo: University de Montreal.

Schaufeli, W. B., \& Bakker, A. B. 2003. Utrecht work engagement scale: Preliminary manual. Occupational Health Psychology Unit, Utrecht University, Utrecht.

Schaufeli, W.B., Salanova, M., Gonzalez-Roma, V. and Bakker, A.B. 2002. The measurement of engagement and burnout: a two sample confirmatory factor analytic approach. Journal of Happiness Studies, Vol. 3 No. 1, pp. 71-92.

Susetyo, Sri Agus. 2015. Keterkaitan antara kepemimpinan transformasional, makna kerja, karakteristik pengikut dan keterlibatan kerja. Pascasarjana UNS. Jurnal Nasional. Vol. 4. Call of Paper UKSW.

Xanthopoulou, D., Bakker, A. B., Demerouti, E., \& Schaufeli, W. B. 2009a. Work engagement and financial returns: A diary study on the role of job and personal resources. Journal of Occupational and Organizational Psychology, No. 82, pp. 183-200.

Xanthopoulou, D., Bakker, A. B., Demerouti, E., \& Schaufeli, W. B. 2009b. Reciprocal relationships between job resources, personal resources, and work engagement. Journal of Vocational Behavior, No. 74, pp. 235-244. 